\title{
SUBSIDIZED CONTRACEPTION, FERTILITY, AND SEXUAL BEHAVIOR
}

\author{
Melissa S. Kearney and Phillip B. Levine*
}

Abstract-We examine the impact of recent state-level Medicaid policy changes that expanded eligibility for family planning services to higherincome women and to Medicaid clients whose benefits would expire otherwise. We show that the income-based policy change reduced overal births to non-teens by about $2 \%$ and to teens by over $4 \%$; estimates suggest a decline of $9 \%$ among newly eligible women. The reduction in fertility appears to have been accomplished via greater use of contraception. Our calculations indicate that allowing higher-income women to receive federally funded family planning cost on the order of $\$ 6,800$ for each averted birth.

\section{Introduction}

$\mathrm{R}$ OUGHLY one-third of all births between 1997 and 2002 in the United States were unintended by the mother based on data available from the National Center for Health Statistics (2005). This rate skyrockets to almost three-quarters for births to teens. A popular response to such jarring statistics is to increase access to family planning services that can help provide the means necessary to reduce unintended childbearing. In fact, a 2006 public opinion poll found that $89 \%$ of American adults believe that people "should have more access to information about birth control options," and $81 \%$ believe that "providing people with access to birth control is a good way to prevent abortions" (Wall Street Journal Online, 2006).

On its face it might seem obvious that providing contraception to women will reduce the number of unwanted pregnancies and births. Of course, behavioral responses to policy changes are rarely so straightforward. Women may choose not to take advantage of the services and many who do would have obtained contraception privately otherwise. Women may also increase their level of sexual activity, canceling out the effectiveness of any increased use of contraception. Ultimately, the impact on behavior is an empirical question.

In this paper, we provide evidence on this point by examining recent expansions of eligibility for Medicaid family planning services to women who would not otherwise be covered. Between December 1993 and March 2007, 25 states received waivers from the federal government to extend this coverage (Guttmacher Institute, 2007a). A brief

Received for publication April 17, 2007. Revision accepted for publication October 24, 2007

* Department of Economics, University of Maryland, and NBER; Department of Economics, Wellesley College, and NBER.

The authors thank Bill Evans, Adam Sonfield, Ted Joyce, two anonymous referees, and seminar participants at the University of Maryland, the University of Connecticut, the University of Virginia, the University of Chicago, Suffolk University, George Washington University, the Rand Corporation, the Brookings Institution, and the 2006 APPAM meetings in Madison, WI, for helpful comments. We also thank Stanley Henshaw, Kosali Simon, Adam Sonfield, and Christopher Rogers for their assistance in obtaining some of the data used in our analysis. Rebecca Vichniac and Daniel Theisen provided outstanding research assistance. We also gratefully acknowledge funding from NICHD (grant number R03 HD052528). Any views expressed are those of the authors alone. review of several states' waiver requests shows that an important goal of these waivers is to reduce unintended pregnancies. We evaluate the effectiveness of these waivers in reducing births, as well as their impact on abortions, sexual activity, and contraceptive use. Because these policies were introduced in different states at different times, we are able to employ difference-in-difference methods to identify a causal connection. We implement these methods using a wide array of data sources, including Vital Statistics birth data, abortion data from the Guttmacher Institute, and microdata from the 1988, 1995, and 2002 National Surveys of Family Growth (NSFG) regarding sexual activity and contraceptive use. We also confirm that these waivers increased the number of women receiving Medicaid-funded family planning services using data from the Centers for Medicare and Medicaid Services (CMS).

The results of our analysis show that one type of these waivers, those that increase income limits for eligibility, were particularly effective. We show that these policies dramatically increased the number of women receiving Medicaid-funded family planning services. We go on to demonstrate that they reduced overall births to non-teens by about $2 \%$ and to teens by over $4 \%$. Scaling these estimates by the estimated proportion of women in a state made eligible, we find that births to newly eligible non-teens fell by almost $9 \%$. Our analysis of individual-level data from the NSFG implies that the reduction in fertility associated with income-based waivers is attributable to greater contraceptive use; we find no evidence of an effect on sexual activity. Based on the cost per recipient of family planning services, we find that each birth that was avoided cost on the order of $\$ 6,800$.

\section{Background}

\section{A. Literature Review}

Though advocacy groups, politicians, and much of the public appears to be optimistic about the potential to decrease rates of unwanted births and abortions by expanding access to contraception, there is very little empirical evidence to date supporting this notion. Kirby (1997, 2001) provides two extensive reviews of the literature on the effectiveness of teen pregnancy prevention programs in the United States, focusing on experimental and quasiexperimental analyses. Although his 1997 review concludes that "there is remarkably little research evidence" to support the conclusion that family planning services prevent teen pregnancies, his 2001 review is somewhat more optimistic. There he reports some evidence that programs offering a large number of services, including family planning, may be effective. DiCenso et al. (2002) provide a similar review of programs like this in a larger set of developed countries. 
They conclude that the types of programs "evaluated to date do not delay the initiation of sexual intercourse, improve use of birth control among young men and women, or reduce the number of pregnancies in young women." Paton (2002) uses difference-in-difference methods to examine the impact of a policy implemented in the United Kingdom in which parental consent was required before family planning services could be provided to those under the age of 16 . He finds no evidence that this restriction on family planning access had any impact on pregnancies or abortions.

There also have been previous studies examining the relationship between geographic measures of contraceptive access and sexual outcomes (cf. Lundberg \& Plotnick, 1990; Mellor, 1998; and Averett, Rees, \& Argys, 2002). In general, these studies differ from ours in emphasis and scope and, furthermore, the sources of identifying variation are arguably not independent of the demand for contraception.

The Medicaid expansion policy that we evaluate differs from previously reviewed "pregnancy prevention" programs in that it was not limited to teenagers. It was broadbased, affecting women in multiple states and varied locales, as opposed to a single community initiative aimed at reducing pregnancy among a very specific teen population. Furthermore, the policy change is specifically about expanded access to family planning services, as opposed to a range of services including educational or job training. Finally, the waivers were directed at women who were not at the very bottom of the income distribution. On the one hand, such women may be more responsive to such interventions. On the other hand, they may be more likely to have been using contraception previously, paid for either through a private health insurance employer or out of pocket. Therefore, past evidence does not adequately inform the issue of the effectiveness of the Medicaid family planning expansions.

Going back further in time provides an example of expanded contraceptive access that has had a significant impact on women's fertility. Recent evidence has examined the introduction of the birth control pill in 1960 and the laws that regulated teens' access to it through the 1960s and 1970s. Bailey (2006) reports that as states relaxed restrictions on teens' ability to obtain the pill, the likelihood of experiencing a first birth by age 22 fell by $16 \%$. Although this intervention is considerably different from that which we explore, it does suggest that it is possible for greater contraceptive access to reduce fertility.

To date, two studies of which we are aware have explored the impact of Medicaid family planning waivers directly. Edwards, Bronstein, and Adams (2003, which was reported in Gold, 2004) examine the impact of family planning waivers granted to six states, but the study has serious methodological weaknesses. In particular, the authors estimate the number of births averted based upon the deviation from prewaiver birth levels within each state; no control group is used to provide an idea of what would have happened to birth rates in the state had no waiver been granted. Lindrooth and McCollough (2007) address this problem, introducing a differences-in-differences framework. They find income-based waivers reduced fertility by about 2 percentage points. Our work also uses a differencesin-differences strategy, but makes important additional contributions relative to their work, adding specification checks, an examination of potential mechanisms, third differences, and the like, in further assessing the causal nature of the results.

\section{B. Institutional Details}

Historically, the main source of public support for family planning services in the United States has been Title X of the Public Health Service Act (commonly referred to as Title X), introduced in 1970. This program is still an important source of public funds for family planning services, but its budget has shrunk considerably in real terms over the past couple of decades. The Medicaid system has also provided access to family planning services to its clients since 1972, but the stringent eligibility requirements to receive Medicaid meant that historically only the very low-income and only women with children had access to these services. A series of expansions in the 1980s extended eligibility for pregnancy-related care, including family planning services for sixty days postpartum. In addition, adolescents have had access to family planning services through the State Children's Health Insurance Program (SCHIP), which was implemented in the late 1990s. Despite the coverage of family planning provided by SCHIP, Gold and Sonfield (2001) report that the take-up rate of this provision among adolescents is quite low, in part because of the lack of confidentiality in their provision.

Between 1994 and 2001, federal Medicaid spending on family planning more than doubled, increasing from \$332 million to $\$ 770$ million. It rose from $46 \%$ of total federal spending on family planning to $61 \%$. During this time the federal government allowed states to implement programs that offer family planning services to women whose incomes would have been too high under the existing Medicaid program or to women who otherwise would have lost Medicaid eligibility, typically postpartum. These waivers allow states to offer the full range of family planning services it offers to its regular Medicaid recipients to additional women. Family planning services provided include a full range of contraceptive methods as well as associated examinations and laboratory tests. The federal government reimburses the state Medicaid program for $90 \%$ of these services and supplies. States may include other related care in their package of benefits, including treatment for STDs, but these services are reimbursed by the federal government at the regular rate, which ranges from 50\% to $76 \%$ of cost (Frost, Sonfield, \& Gold, 2006). Seventeen states cover abortion under their Medicaid program, but federal funds 
Table 1.-States with Section 1115 Medicaid Family Planning Waivers

\begin{tabular}{|c|c|c|c|c|c|}
\hline \multirow[b]{2}{*}{ State } & \multirow[b]{2}{*}{ Date Approved } & \multirow[b]{2}{*}{ Date Implemented } & \multicolumn{3}{|c|}{ Basis for Eligibility } \\
\hline & & & $\begin{array}{l}\text { Losing Coverage } \\
\text { Postpartum }\end{array}$ & $\begin{array}{l}\text { Losing Coverage } \\
\text { for Any Reason }\end{array}$ & $\begin{array}{l}\text { Based Solely on } \\
\text { Income (FPL) }\end{array}$ \\
\hline Alabama & $7 / 1 / 2000$ & $10 / 1 / 2000$ & & & $133 \%$ of poverty \\
\hline Arizona & $4 / 1 / 1995$ & $8 / 1 / 1995$ & 2 years & & \\
\hline Arkansas & $6 / 18 / 1996$ & $9 / 1 / 1997$ & & & $200 \%$ \\
\hline California & 1/1/1997 & $1 / 1 / 1997$ & & & $200 \%$ \\
\hline Delaware & $5 / 17 / 1995$ & $1 / 1 / 1996$ & & 2 years & \\
\hline Florida & $8 / 23 / 1998$ & 9/1/1998 & 2 years & & \\
\hline Illinois & $6 / 23 / 2003$ & $4 / 1 / 2004$ & & 5 years & \\
\hline Iowa & $1 / 10 / 2006$ & $2 / 1 / 2006$ & & & $200 \%$ \\
\hline Louisiana & $6 / 6 / 2006$ & $7 / 1 / 2006$ & & & $200 \%$ \\
\hline Maryland & $12 / 5 / 1994$ & $2 / 1 / 1995$ & 5 years & & \\
\hline Michigan & $3 / 1 / 2006$ & $7 / 1 / 2006$ & & & $185 \%$ \\
\hline Minnesota & $7 / 20 / 2004$ & $7 / 1 / 2006$ & & & $200 \%$ \\
\hline Mississippi & $1 / 31 / 2003$ & $10 / 1 / 2003$ & & & $185 \%$ \\
\hline Missouri & $4 / 29 / 1998$ & 2/1/1999 & 1 year & & \\
\hline New Mexico & $8 / 1 / 1997$ & $7 / 1 / 1998$ & & & $185 \%$ \\
\hline New York & $9 / 27 / 2002$ & $10 / 1 / 2002$ & & & $200 \%$ \\
\hline New York & $9 / 27 / 2002$ & $10 / 1 / 2002$ & 2 years & & \\
\hline North Carolina & $11 / 5 / 2004$ & $11 / 5 / 2005$ & & & $185 \%$ \\
\hline Oklahoma & $11 / 5 / 2004$ & $4 / 1 / 2005$ & & & $185 \%$ \\
\hline Oregon & $10 / 14 / 1998$ & 1/1/1999 & & & $185 \%$ \\
\hline Rhode Island & $11 / 1 / 1993$ & $8 / 1 / 1994$ & 2 years & & \\
\hline South Carolina & $1 / 1997$ & $7 / 1 / 1997$ & & & $185 \%$ \\
\hline South Carolina & $12 / 1993$ & $7 / 1 / 1994$ & 2 years & & \\
\hline Texas & $12 / 21 / 2006$ & $1 / 1 / 2007$ & & & $185 \%$ \\
\hline Virginia & $7 / 22 / 2002$ & $10 / 1 / 2002$ & 2 years & & \\
\hline Washington & $3 / 6 / 2001$ & $7 / 1 / 2001$ & & & $200 \%$ \\
\hline Wisconsin & $6 / 14 / 2002$ & $1 / 1 / 2003$ & & & $185 \%$ \\
\hline
\end{tabular}

Notes: Waivers in Alabama, Illinois, Louisiana, Michigan, New Mexico, North Carolina, and Oklahoma are restricted to individuals age 19 and older. The dates for California correspond to policies funded by the state; federal financing of these waiver policies commenced two years later.

Sources: Frost et al. (2006), http://www.guttmacher.org/statecenter/spibs/spib_MFPW.pdf (accessed 9/28/05), http://www.cms.hhs.gov/medicaid/waivers/waivermap.asp (accessed 9/28/05), and Guttmacher Institute (2006), http://www.guttmacher.org/statecenter/spibs/spib_SMFPE.pdf (accessed 9/2/06).

may not be used for abortion and hence abortion services are not provided under these waiver provisions.

Beginning with South Carolina in 1993 and most recently with Texas at the end of 2006, 25 states have applied for and received waivers to extend eligibility for these family planning services to women who would not otherwise be covered. Table 1 lists the provisions enacted in each state along with the dates they were approved and implemented. Eight states currently have waiver policies in place to extend coverage to women who would otherwise lose the sixty-day postpartum coverage of family planning services. Two other states extend coverage of family planning services for up to two years and five years for women who would lose Medicaid eligibility for any reason, not just postpartum. For the remainder of this analysis, we will collectively refer to these two types as duration waivers. An additional seventeen states have been granted waivers to extend Medicaid family planning services based solely on income, regardless of categorical eligibility requirements (such as having a dependent child); this income threshold is set to $133 \%$ of the federal poverty line in one state, $185 \%$ of the federal poverty line in eight states, and to $200 \%$ of the poverty line in the remaining seven states. We refer to these seventeen policies as income-based waivers. Both South Carolina's and New York's waivers extend coverage to both women losing eligibility postpartum as well as women under the income threshold.

\section{The Impact of Waivers on the Number of Public Family Planning Recipients}

Before examining the impact of waivers on fertility outcomes, we undertake an analysis to determine whether the policy change increased the number of women who received Medicaid family planning services. If more people are not going through the front door of the Medicaid-funded family planning provider, then it is unlikely that the program had any behavioral effects.

Although this is a useful first step in our analysis, it is important to consider two important limitations in interpreting its results: crowdout and spillover. Crowdout refers to the possibility that some women who receive family planning services through the Medicaid program after the waiver would have used privately provided family planning services in the absence of a waiver. This merely changes the form of payment, not the services provided, and should have no behavioral impact. Spillover refers to the possibility that the introduction of a waiver increases program awareness and increases visibility of family planning clinics, which increases the take-up of services among women who were previously eligible for Medicaid family planning services but not receiving them. In this instance we might see an increase in contraceptive use and a corresponding fertility response that is greater than that due to newly eligible women alone. Identifying the impact of the policy on 
Table 2.--Impact of Waivers on the Number of Medicaid Family Planning Clients as a Proportion of the Female Population Age 15-44

\begin{tabular}{|c|c|c|c|c|}
\hline & $\begin{array}{l}\text { Mean Proportion Medicaid } \\
\text { FP Clients in } 1992 \\
\text { (1) }\end{array}$ & $\begin{array}{c}\text { No State Trends } \\
\text { (2) }\end{array}$ & $\begin{array}{c}\text { Linear State Trends } \\
\text { (3) }\end{array}$ & $\begin{array}{c}\text { Quadratic State Trends } \\
\text { (4) }\end{array}$ \\
\hline Income-based waiver & 0.046 & $\begin{array}{c}0.116 \\
(0.027)\end{array}$ & $\begin{array}{c}0.088 \\
(0.024)\end{array}$ & $\begin{array}{c}0.053 \\
(0.013)\end{array}$ \\
\hline Duration-based waiver & 0.037 & $\begin{array}{l}-0.006 \\
(0.007)\end{array}$ & $\begin{array}{c}0.013 \\
(0.011)\end{array}$ & $\begin{array}{c}0.012 \\
(0.008)\end{array}$ \\
\hline Neither & 0.044 & - & - & - \\
\hline Number of observations & - & 538 & 538 & 538 \\
\hline
\end{tabular}

Notes: Columns 2 to 4 report results from separate regressions where the dependent variable is the proportion of the female population age 15-44 who received Medicaid family planning services. All regressions control for state and year fixed effects, the state unemployment rate, the maximum welfare benefit for a family of three in the state-year, and whether the following policies were in place in the respondent's state at the beginning of the survey year-welfare family cap, TANF, SCHIP, Medicaid coverage of abortion, abortion parental notification requirements, abortion delay rules, and mandated private health insurance coverage of family planning services. They also control for the percentage of the state-year female population in the following demographic groups: married, white, Hispanic, four education groups, and age 15-17, $18-19,20-24,25-29,30-34$, and 35-39. All regressions are weighted by the population of women age 15 to 44 in the state and year. Standard errors are adjusted for clustering at the state level. Data on Medicaid $18-19,20-24,25-29,30-34$, and 35-39. All regressions are weighted by the population of women age 15 to 44 in the state and year. Standard errors are adjusted for clustering at the state level. Data on Medicaid
family planning beneficiaries for the years 1999-2002 are from the Medicaid Statistical Information System (MSIS), downloaded from http://www.cms.hhs.gov in December 2006. Comparable data for 1992-1998 come from national HFCA-2082 tables, graciously provided to us by Kosali Simon.

overall contraceptive use in light of both crowdout and spillover issues would require data on all women's use of family planning services; unfortunately no such data are available.

Instead we make use of publicly available data from the Medicaid Statistical Information System (MSIS) of the Centers for Medicare and Medicaid Services (CMS), the basic source of state-submitted eligibility and claims data on the Medicaid population. State-by-state tables are available for fiscal years 1999 to 2002 that contain information on the number of Medicaid beneficiaries with family planning claims. We obtained comparable data for the years 1992 and 1998 from the older national HFCA-2082 tables. ${ }^{1}$ Finding an effect on service receipt from these data is a necessary, but not sufficient, condition in identifying any behavioral effects that may have resulted from the introduction of the waivers.

We use these data to estimate a simple ordinary least squares regression of the proportion of women 15-44 receiving Medicaid family planning services on indicator variables for the implementation of income-based and duration-based waivers along with state and year fixed effects. In its simplest form, this approach is equivalent to a difference-in-difference estimator. We also add to these regressions a full set of control variables (described in more detail subsequently), holding constant other state-level policy changes and changes in demographic characteristics of state populations over time. Finally, we experiment with alternative forms of trends within states over time, including no state-specific trends as well as linear and quadratic state-specific trends.

Table 2 reports the results of this analysis. Column 1 provides the 1992 (prior to any waiver) values of the

\footnotetext{
${ }^{1}$ We are grateful to Kosali Simon for sharing these data with us. These aggregated statistics are not available separately for teens. A visual inspection of these data indicated a handful of data points that clearly represent errors. States with a steady-state positive value of recipients suddenly equal 0 or very near 0 and then revert to values comparable to the earlier values. We chose to recode as missing all states where the proportion of women 15-44 receiving Medicaid family planning services fell below $0.05 \%$. We also tested the sensitivity to the precise cutoff used, but found that it had negligible effects on the results. In total, we recoded 23 observations to missing.
}

proportion of women 15-44 receiving Medicaid family planning services in states that implemented income and duration waivers by 2002 (the last year of data availability). The results indicate that $4.6 \%$ and $3.7 \%$ of women were receiving those services in the two respective types of states. These estimates provide a reference point to help interpret the magnitude of the results from this regression analysis.

The regression estimates reported in the remainder of the table provide clear evidence that income-based waivers increased the number of women receiving family planning services through the Medicaid program. Columns 2-4 present these results, where each column represents the results from a separate regression. The coefficient estimates from all three specifications indicate that the number of recipients increased tremendously, on the order of two to three times depending upon specification, in response to an income-based waiver. Later in the paper we describe a procedure for estimating the percentage of the female population ages 20-44 that would be newly eligible for Medicaid family planning services under these waivers and obtain an average figure across states of $22.5 \%$. Combining the results here of a 5 to 10 percentage point increase in the share of the population receiving Medicaid family planning services, this implies an average take-up rate in the vicinity of $22 \%$ to $44 \%$ among those whose eligibility was affected by the policy.

Once state trends are added, duration-based waivers also are estimated to have a modest impact on benefit receipt, but these estimates are not statistically significant. Given the size of the estimates, we interpret these results as ruling out large effects, but not ruling out something less than that.

We conclude from this analysis that we have at least established a basis to further examine the impact of these policy changes, and particularly income-based waivers, on behavioral outcomes. The potential for crowdout of privately funded contraceptive use means that the increase in the number of Medicaid family planning recipients need not have led to any change in contraceptive behavior or fertility outcomes. This is an empirical question that we address subsequently. 


\section{Estimating the Impact on Births and Abortions}

\section{A. Econometric Methodology}

To investigate the impact of expanded eligibility for Medicaid family planning services on births and abortions, we use difference-in-difference methods exploiting the variation across states in the timing of program implementation, as detailed in table 1. Specifically, we begin our analysis by estimating ordinary least squares regression models of the following form:

$$
\begin{aligned}
\ln Y_{s t}= & \beta_{0}+\beta_{1}(\text { inc. waiver })_{s t}+\beta_{2}(\text { dur. waiver })_{s t} \\
& +\beta_{3} X_{s t}+\gamma_{s}+\gamma_{t}+\varepsilon_{s t} .
\end{aligned}
$$

In this model, $Y_{s t}$ is defined alternatively as the birth or abortion rate in state $s$ at time $t$. The regressors of interest, inc. waiver $_{\text {st }}$ and dur. waiver $_{s t}$, equal 1 if an income-based or duration-based Medicaid family planning waiver is implemented in state $s$ at time $t$ and equal 0 otherwise. In the year in which the waiver was passed the regressors are equal to a fraction between $(0,1)$ based on the number of months the waiver was in effect. We modify this specification to include state-specific linear and quadratic time trends to control for the possibility of a spurious correlation between the introduction of waivers and trends in fertility outcomes across states. All reported regressions are weighted by the state population for the relevant population subgroup, but results are qualitatively similar in unweighted models. Standard errors are clustered at the state level.

It is also important that these regressions control for other observable state-specific factors that might have changed over time, including other relevant policy changes. During the period we focus on, these include important changes to abortion restrictions (parental notification/consent, waiting periods, and Medicaid funding of abortion), the welfare system (maximum AFDC/TANF benefit for a family of three, a welfare reform indicator, and a "family cap" indicator), and other Medicaid policies (an indicator for SCHIP implementation). ${ }^{2}$ In addition, a number of states introduced mandates requiring health insurance coverage of contraception. We include indicator variables representing whether these policies were in place in each state/year. ${ }^{3}$ In addition, we include the state unemployment rate to control for

\footnotetext{
${ }^{2}$ See Levine (2004) for a description of abortion law changes. Information on welfare reform policies were obtained from three sources: (i) a technical report of the Council of Economic Advisers (1999); (ii) an Urban Institute report written by Gallagher et al. (1998); and (iii) a report by Crouse (1999), prepared for the U.S. Department of Health and Human Services, which summarizes information contained in a report of the U.S. Department of Health and Human Services (1997). SCHIP implementation dates were obtained from the CMS Web site (http://www.cms.hhs. gov/schip/enrollment/fy2000.pdf), accessed September 2005. Data on welfare benefit levels were obtained from Council of Economic Advisers (1997) and Rowe, McManus, and Roberts (2004), Rowe and Russell (2004), and Rowe and Versteeg (2005).

${ }^{3} \mathrm{We}$ are grateful to Adam Sonfield at the Guttmacher Institute for providing us with data on these policies.
}

differences in local labor market conditions that may affect women's decisions/opportunity cost regarding having children. Finally, these regressions include a set of the average demographic characteristics, including the age and race composition, educational attainment, and marital status of women in the state/year. These variables were created using data from the outgoing rotation group files from the Current Population Survey, available from the National Bureau of Economic Research.

We estimate this equation separately for teens and for non-teens as well as for population subgroups distinguished by age, race/ethnicity, and educational attainment. Our set of "treatment states" is composed of the states that implemented income-based waivers (Alabama, Arkansas, California, New Mexico, Oregon, South Carolina, and Washington) and duration-based waivers (Arizona, Delaware, Florida, Maryland, Missouri, Rhode Island, and South Carolina) during our sample period. New York and Virginia implemented waivers in the last quarter of the final year in the sample period and are not considered treatment states for the purpose of this discussion or in the figures, but in the regressions the relevant waiver indicator associated with the state observation is set equal to 0.25 in the final year. For models including only teens, we drop observations from Alabama and New Mexico because the waiver policies in these states explicitly excluded females under the age of 19 .

One important consideration in analyses like this is the potential for policy endogeneity (Besley \& Case, 2000). In this case, one might expect that states having greater trouble with unwanted pregnancies may be more likely to adopt more aggressive family planning policies. The bias in such an environment, however, would go in the direction of finding a positive relationship between, say, teen childbearing and family planning, not a negative one, as we are finding. Moreover, we undertake various analyses to confirm that we are finding a causal relationship between the policy and subsequent fertility. We compare the estimated impact on birth rates across demographic groups differentially affected within a state by the policy (across education and age groups, for example). In our analysis of individuallevel data from the NSFG on sexual and contraceptive behavior we introduce an explicit within-state comparison by considering separately the impact on women predicted to have been made newly eligible for family planning services. The results of these analyses bolster the contention that policy endogeneity is not driving our results.

\section{B. Data}

We use several sources of data to estimate these models, where the different data sources are necessary to capture different components of fertility-related behavior. For births, we use Vital Statistics natality data aggregated to the state level. These birth data are very well measured in the aggregate as well as for several population subgroups, including by state of residence, age, race/ethnicity, and 
educational attainment. ${ }^{4}$ The Census Bureau also provides population estimates by state/year by age, gender, and race/ethnicity, so we can combine these two sources of data to generate birth rates for these subgroups. We use data on weeks of gestation to convert the dating of births from their year of occurrence to the year of their conception. ${ }^{5}$ We start with births that occur in 1990 through 2003 (the most recent year available at the time we began this study) and convert them to births that were conceived in 1990 through 2002. All other explanatory variables are merged onto these data to correspond to the year of conception.

Data on abortions come from the Guttmacher Institute. Their abortion data are obtained from surveys of abortion providers, inquiring about the number of procedures performed in the past year (or in the year before that). These data are generally recognized as the most accurate available. Abortion counts are recorded by the location of the provider, however, not the state of residence of the women having abortions. The Guttmacher Institute takes advantage of other available data from the Centers for Disease Control (CDC) to generate abortion counts by state of residence. CDC data tend to provide an undercount of the number of abortions provided (Guttmacher Institute, 1997), but those data include information on the state of occurrence of the abortion and the state of residence of the woman. Guttmacher uses these data to transform their occurrence-based data to residence-based data; we use those data in our analysis. ${ }^{6}$ During our sample period, they are available for 1991, 1992, 1996, 1999, and 2000. Similarly, for teen abortions Guttmacher has adopted a set of assumptions designed to create a set of estimated teen abortion rates by state of residence for the years 1992, 1996, 1999, and 2000 (Henshaw, 1997; Henshaw \& Feivelson, 2000; and Guttmacher Institute, 2006); we use these data as well.

\section{Descriptive Statistics}

Descriptive statistics regarding national trends in births and abortions can be found in published sources. For all women of childbearing age, the birth rate fell slightly in the early 1990s, but has been reasonably stable since then (Martin et al., 2005). The abortion rate, on the other hand, has fallen steadily over the period (Finer \& Henshaw, 2003). In 1991, 26.3 abortions were performed for every 1,000

\footnotetext{
${ }^{4}$ Vital Statistics data on births are also available by maternal marital status, but these data are not reliably measured because of the imputation of marital status, often based on the last names of the parents, in some states and changes in the method of recording marital status during the sample period (see the 1997 technical appendix from the Vital Statistics of the United States: Natality). Due to this limitation, we have chosen to omit an analysis using these data.

${ }^{5}$ The weeks of gestation variable contains some missing data. For those births missing this information, we assumed that the pregnancy lasted forty weeks, which was the modal value in these data. We also experimented with predicting the length of gestation to replace the missing values using birthweight and maternal age and education as regressors, but we obtained virtually identical results using this approach.

${ }^{6}$ These data have been graciously provided to us by Stanley Henshaw at AGI.
}

women of childbearing age (15-44), but that level fell to 21.3 in 2000 (the latest year for which Guttmacher Institute data are available). For teens, the birth rate in the United States has fallen dramatically since the early 1990s, starting that decade at over 60 births per 1,000 women aged 15-19 and falling to a rate of 41.6 in 2003 (Guttmacher Institute, 2006). At the same time, the teen abortion rate has fallen from 35.2 abortions per 1,000 women aged 15-19 in 1992 to a rate of 24.0 in 2000.

Note that this is the period that waivers were introduced. Of course, it would be premature to draw any conclusions from these aggregated statistics regarding whether these patterns of behavior could be attributed to the expansion of eligibility for Medicaid family planning services in particular states. We turn our attention to an econometric analysis of this question in the following section.

\section{Results}

Before reporting the results of our full econometric analysis, we begin with figures 1 and 2, which display trends in birth rates for all non-teens and teens, respectively, for states that are distinguished by their waiver status. Because the waivers were introduced at different times, we scale the $x$ axis according to the year relative to that in which the waiver was implemented. We set "year 0" for nonwaiver states to be 1997 since this is in the middle of the sample period and a year in which several waivers were implemented. To maintain a balanced sample and still display as many years as possible, we limit the exercise to the four years prior to the waiver and two years following it. The state of Washington still needed to be eliminated from this analysis as an income-waiver state because we do not have two years of postwaiver data.

In figure 1 we see that birth rates for non-teens in states are converging across the three groups of states; this pattern starts before any waivers were introduced and highlights the importance of holding constant state trends. The observed pattern also suggests that the underlying trend is potentially best described by a quadratic functional form. There does not seem to be any dramatic decline in birth rates among non-teens in waiver states in later years relative to the non-waiver states. This does not rule out the existence of a treatment effect, but it does suggest that any such effect is unlikely to be very large at an aggregate level. Birth rates for teens (figure 2) appear to have dipped in states that implemented income-based waivers, but this large decline precedes the waiver's introduction and is unlikely to be attributable to the waiver directly. Again, the differential trends across states highlight the need to control for this in the econometric models that we estimate.

Table 3 reports estimates from regression models of the form of equation (1), where the dependent variable represents the log of the birth rate (top panel) and the log of the abortion rate (bottom panel). Results are presented for teens and non-teens separately for births and for teens and all 
Figure 1.-Trend in Non-TeEn Birth Rates by Waiver Status

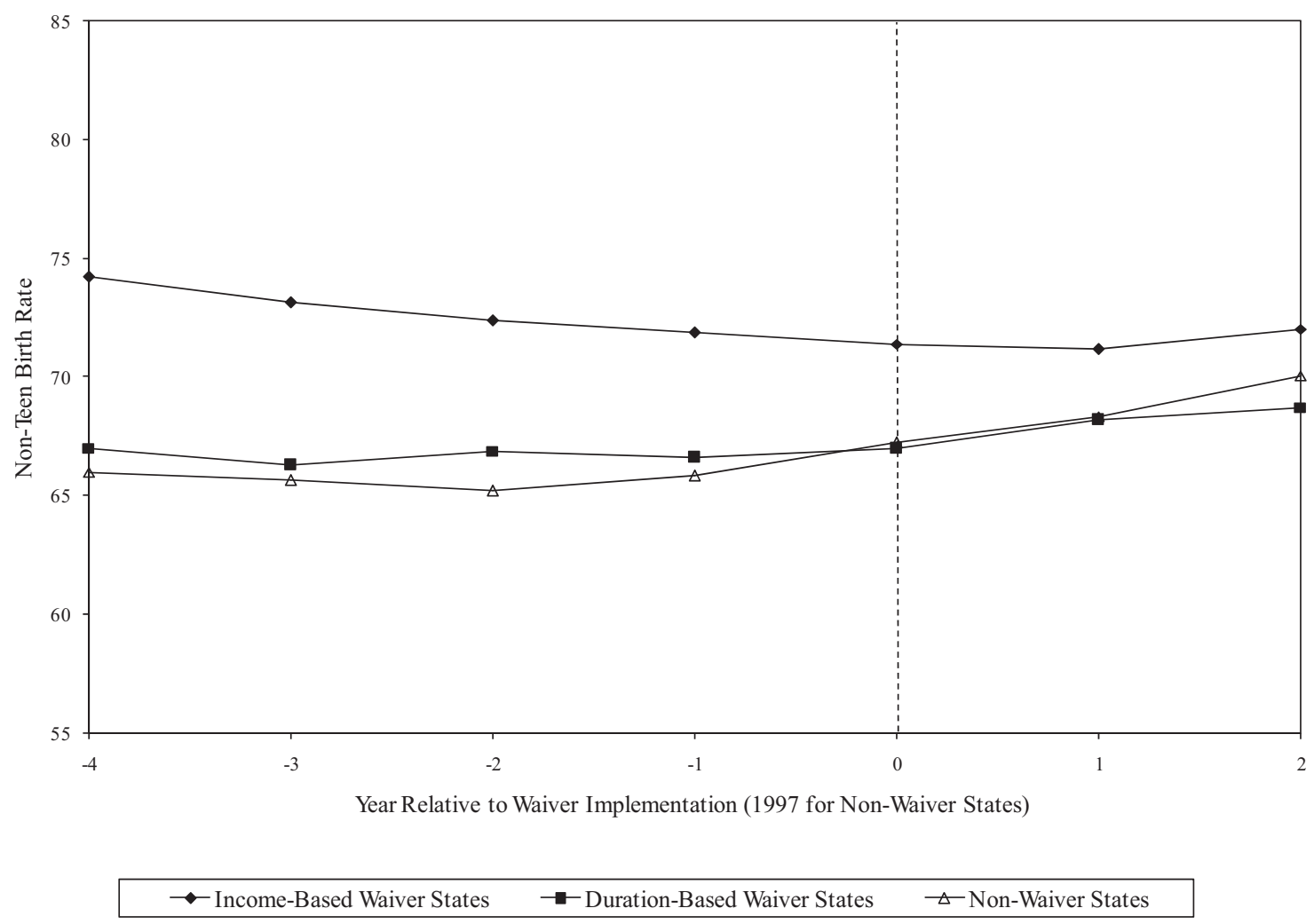

women (mostly non-teens) for abortions. We report models that include no state-specific linear trends as well as linear and quadratic trends to examine the sensitivity of the results to these alternative specifications.

The results provide strong evidence that income-based family planning waivers reduce births, particularly for teens. For teens and non-teens in models without statespecific trends, births are estimated to fall by about $7.1 \%$ and $5.3 \%$, respectively. As predicted earlier, including state trends reduces the size of the estimated effects to $4.7 \%$ and $1.7 \%$. Quadratic trends have little impact on the estimates; these waivers are found to reduce births by $4.2 \%$ and $2.0 \%$ for teens and non-teens, respectively.

The results for duration waivers are less robust. The point estimates are close to 0 and statistically insignificant for teens. When estimated among non-teens, all point estimates are negative, and are statistically significant for non-teens in models with no trends and linear state trends, but statistically insignificant in the model with quadratic state trends. We believe that these findings are suggestive that these waivers might have an impact on reducing fertility for non-teens, but the evidence is not sufficient to strongly support that conclusion. Similar results were obtained regarding the number of family planning recipients, as reported in figure 2, supporting this conclusion. For the remainder of the analysis we focus more of our attention on income-based waivers.
The bottom panel of table 3 conducts similar analyses regarding abortion rates. Because we have more data available for women 15-44 than we do for teens, we estimate models for women 15-44, rather than for non-teens, 20-44. Data limitations, described earlier, reduce the sample size of available state/year cells relative to that in the birth regressions, particularly for teens (results for non-teens using the same sample years as teens are similar to those reported). The results of this analysis provide little evidence of an impact on abortion rates attributable to the introduction of a family planning waiver. The problem is largely about imprecision; standard errors of $10 \%$ or more suggest that the impact on abortion rates would have to be enormous before one could reject a null hypothesis of no effect. For women 15-44, standard errors are somewhat smaller, but they are still large enough that only very large effects could be statistically significant. The point estimates are sensitive to empirical specification and never large enough to be significant. This is not conclusive evidence that family planning waivers have little or no effect on abortions, but rather it indicates that we are uable find any evidence in support of such an effect.

Table 4 extends our analysis of the impact on birth rates by examining different population subgroups (columns 1 and 2). All results reported here are based on specifications that include state-specific quadratic trends. When women are differentiated by their age, we see that 
Figure 2.-TRend in TeEn Birth Rates by Waiver Status

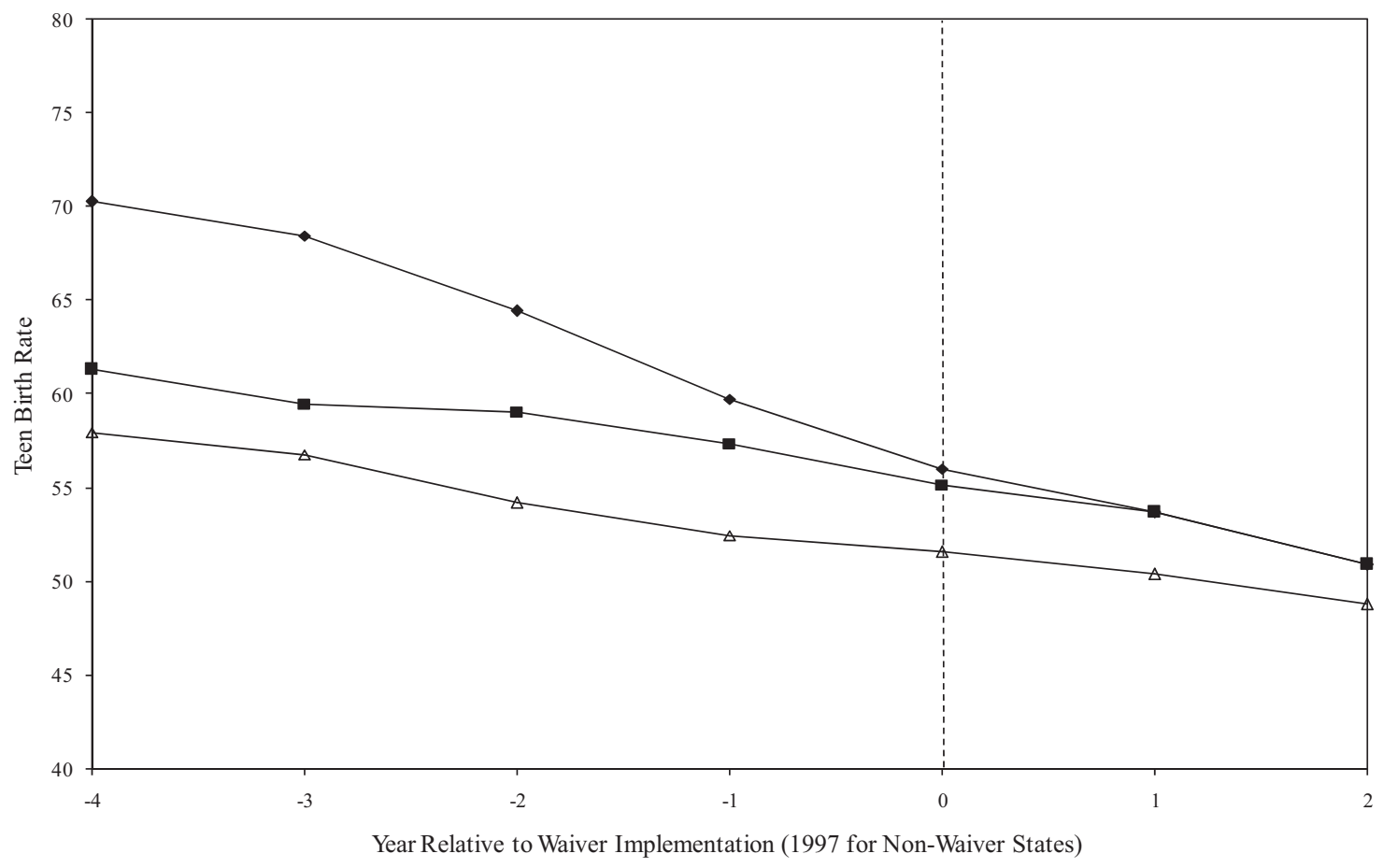

$\bullet$ Income Based Waiver States $\rightarrow$ Duration Based Waiver States $\triangle$ Non-Waiver States

income-based waivers have the largest impact on women 18-19 and 20-24 years of age. Estimates for other age groups are not statistically significant. By race, there are differences in point estimates for the impact of incomebased waivers, but these differences are not statistically significant.
The bottom panel of the table examines births to women with different levels of educational attainment. For this analysis, we use the natural log of the number of births to women in each category because we do not have relevant population numbers to create birth rates (age and race results using numbers of births are similar to those reported

Table 3.-Impact of Medicaid Family Planning Waivers on Births and Abortions for TeEns and Non-Teens

\begin{tabular}{|c|c|c|c|c|c|c|}
\hline & & & & \multicolumn{3}{|c|}{ Births: Non-Teens (20-44) } \\
\hline & \multicolumn{3}{|c|}{ Teens (15-19) } & \multicolumn{3}{|c|}{ Abortions: All Women (15-44) } \\
\hline & $\begin{array}{l}\text { No State } \\
\text { Trends }\end{array}$ & $\begin{array}{c}\text { Linear State } \\
\text { Trends }\end{array}$ & $\begin{array}{c}\text { Quadratic State } \\
\text { Trends }\end{array}$ & $\begin{array}{l}\text { No State } \\
\text { Trends }\end{array}$ & $\begin{array}{l}\text { Linear State } \\
\text { Trends }\end{array}$ & $\begin{array}{c}\text { Quadratic State } \\
\text { Trends }\end{array}$ \\
\hline \multicolumn{7}{|c|}{ Births } \\
\hline Income-based & -0.071 & -0.047 & -0.042 & -0.053 & -0.017 & -0.020 \\
\hline Waiver implemented & $(0.024)$ & $(0.013)$ & $(0.014)$ & $(0.012)$ & $(0.009)$ & $(0.009)$ \\
\hline Duration-based & 0.002 & -0.008 & 0.014 & -0.016 & -0.016 & -0.007 \\
\hline Waiver implemented & $(0.020)$ & $(0.015)$ & $(0.010)$ & $(0.008)$ & $(0.009)$ & $(0.006)$ \\
\hline Number of observations & 637 & 637 & 637 & 663 & 663 & 663 \\
\hline \multicolumn{7}{|c|}{ Abortions } \\
\hline Income-based & -0.085 & 0.064 & 0.175 & -0.039 & 0.121 & 0.075 \\
\hline Waiver implemented & $(0.065)$ & $(0.102)$ & $(0.159)$ & $(0.035)$ & $(0.055)$ & $(0.087)$ \\
\hline Duration-based & 0.010 & -0.073 & -0.040 & 0.064 & 0.012 & -0.071 \\
\hline Waiver implemented & $(0.055)$ & $(0.065)$ & $(0.138)$ & $(0.049)$ & $(0.048)$ & $(0.090)$ \\
\hline Number of observations & 196 & 196 & 196 & 255 & 255 & 255 \\
\hline \multicolumn{7}{|c|}{$\begin{array}{l}\text { Notes: Each column represents the results from separate regressions on the log of the birth or abortion rate in models that also include the following control variables: the unemployment rate, indicator } \\
\text { for whether welfare reforms were implemented (including pre-TANF waivers) and for whether the reforms included a family cap, the maximum AFDC/TANF benefit for a family of three, an indicator fo } \\
\text { whether SCHIP was implemented in the state, indicator variables for whether there are laws restricting abortion access by creating mandatory delays, requiring some form of parental involvement for minors } \\
\text { and restriction on Medicaid funding for abortions, an indicator for whether states have comprehensive contraception coverage, variables measuring the percentage of the state's population that is married } \\
\text { white, or Hispanic. Regressions for women } 20-44 \text { also include the following education and age controls: high school dropout, high school graduate, attended some college, and between the ages of } 15-17 \\
18-19,20-24,25-29,30-34 \text {, and } 35-39 \text {. For the teenage regressions, observations from Alabama and New Mexico are dropped from the analysis sample because these states implemented income-based } \\
\text { waivers that explicitly did not apply to women under the age of } 19 \text {. All regressions are weighted by the relevant population of women in the state and year. Standard errors are reported in parentheses and } \\
\text { are adjusted for clustering at the state level. }\end{array}$} \\
\hline
\end{tabular}


Table 4.--Impact of Medicaid Family Planning Waivers on Overall Births and Births of Eligible Women, by Demographic Group

\begin{tabular}{|c|c|c|c|c|}
\hline & $\begin{array}{l}\text { Income-Based } \\
\text { Waiver } \\
\text { (1) }\end{array}$ & $\begin{array}{l}\text { Duration-Based } \\
\text { Waiver } \\
\text { (2) }\end{array}$ & $\begin{array}{c}\text { Estimated \% Made } \\
\text { Eligible by } \\
\text { Income-Based Waiver } \\
\text { (3) }\end{array}$ & $\begin{array}{c}\text { Impact of Income-Based } \\
\text { Waiver on Eligible } \\
\text { Women in Group } \\
\text { (4) }\end{array}$ \\
\hline \multicolumn{5}{|l|}{ Age group } \\
\hline Age $15-17$ & $\begin{array}{c}-0.012 \\
(0.014)\end{array}$ & $\begin{array}{c}0.019 \\
(0.011)\end{array}$ & - & - \\
\hline Age $18-19$ & $\begin{array}{c}-0.068 \\
(0.018)\end{array}$ & $\begin{array}{c}0.014 \\
(0.016)\end{array}$ & - & - \\
\hline Age $20-24$ & $\begin{array}{c}-0.051 \\
(0.021)\end{array}$ & $\begin{array}{c}0.014 \\
(0.016)\end{array}$ & 34.4 & -0.148 \\
\hline Age $25-34$ & $\begin{array}{c}-0.009 \\
(0.006)\end{array}$ & $\begin{array}{c}-0.001 \\
(0.009)\end{array}$ & 21.9 & -0.041 \\
\hline Age $35-44$ & $\begin{array}{c}-0.007 \\
(0.013)\end{array}$ & $\begin{array}{c}-0.013 \\
(0.008)\end{array}$ & 18.1 & -0.039 \\
\hline Age $20-44$ & $\begin{array}{r}-0.020 \\
(0.009)\end{array}$ & $\begin{array}{c}-0.007 \\
(0.006)\end{array}$ & 22.5 & -0.089 \\
\hline \multicolumn{5}{|l|}{ Racelethnicity } \\
\hline White, non-Hispanic & $\begin{array}{r}-0.010 \\
(0.007)\end{array}$ & $\begin{array}{c}-0.006 \\
(0.008)\end{array}$ & 19.3 & -0.041 \\
\hline Black, non-Hispanic & $\begin{array}{c}-0.013 \\
(0.021)\end{array}$ & $\begin{array}{c}0.002 \\
(0.008)\end{array}$ & 32.1 & -0.040 \\
\hline Hispanic & $\begin{array}{r}-0.029 \\
(0.010)\end{array}$ & $\begin{array}{c}0.029 \\
(0.023)\end{array}$ & 31.2 & -0.093 \\
\hline \multicolumn{5}{|l|}{ Education } \\
\hline High school dropouts & $\begin{array}{r}-0.038 \\
(0.013)\end{array}$ & $\begin{array}{c}-0.052 \\
(0.022)\end{array}$ & 36.8 & -0.103 \\
\hline High school graduates & $\begin{array}{c}-0.028 \\
(0.009)\end{array}$ & $\begin{array}{c}-0.015 \\
(0.007)\end{array}$ & 27.0 & -0.104 \\
\hline Some college & $\begin{array}{c}-0.003 \\
(0.008)\end{array}$ & $\begin{array}{c}-0.010 \\
(0.015)\end{array}$ & 20.3 & -0.015 \\
\hline College graduates & $\begin{array}{c}-0.007 \\
(0.007)\end{array}$ & $\begin{array}{r}-0.016 \\
(0.008)\end{array}$ & 10.1 & -0.069 \\
\hline
\end{tabular}

Notes: Each row in columns 1 and 2 represents the results from separate regressions where the dependent variable is the log of the birth rate (by age and race) or the log of the number of births (by education) in models that all include state-specific quadratic trends. In column 3, statistics reflect the estimated percentage of the population that is eligible for income-based waivers in those states with such waivers in the 2000 Census. Statistics in column 4 reflect the simulated impact of income-based waivers on the eligible population, which is the coefficient in column 1 divided by the percentage (divided by 100) in column 3 . See notes to table 3 for additional $X$ variables in all regressions and other comments.

earlier). We also focus on women 20-44 because so many teens are still enrolled in school. In addition, we restricted the sample period used for this analysis to 1992-2001 because a few states do not have births by educational attainment recorded in the Vital Statistics data for 1990, 1991, and 2002.

The results of this analysis indicate that the impact of income-based waivers decreases with educational attainment. Because eligibility for these waivers is negatively correlated with educational attainment, as discussed subsequently, these findings provide additional support for the notion that our results are identifying a causal impact.

The remainder of the table incorporates the fact that not all women are eligible for the benefits associated with, in particular, an income-based waiver. Duration-based waivers are also targeted at particular population subgroups (women who recently had a child and would otherwise have to give up their benefits), but identifying those subgroups is very difficult in large-scale, publicly available data. On the other hand, we are able to use microdata from the 2000 Census to approximate the fraction of a state's female population in different population subgroups who would be made eligible by an income-based waiver. ${ }^{7}$ We can use these calculated eligibility rates to scale our earlier estimates of the impact of these waivers and arrive at a simulated impact on the eligible population. ${ }^{8}$ We restrict this exercise to the population of women 20-44 because it is not clear how to

\footnotetext{
${ }^{7}$ The eligibility calculations are based upon the eligibility criteria described in Broaddus et al. (2002). They begin by predicting whether a woman's income and family structure would enable her to receive Medicaid in the absence of a waiver and then calculate her eligibility in the presence of an income-based waiver. Our eligibility measure is the increment to the fraction of women eligible in each waiver state. We make no pretense of thoroughly coding eligibility as a function of the complete set of state rules regarding detailed aspects of family income and asset holdings. Our eligibility figures should be considered rough approximations based only on income and family characteristics.

${ }^{8}$ An alternative approach would be to include in the regression an interaction term between estimated eligibility and the waiver indicator variable. Our first attempt to do so included this interaction term along with the waiver indicator, but without any time series variability in our eligibility measure, the results were not estimated with a great deal of precision. Our second attempt included the interaction term without the waiver indicator. The results of that analysis provided point estimates that were virtually identical to those we report in column 4 with $t$-statistics very similar to those reported in column 2 . Our view is that this exercise is doing little more than the scaling that we described and that reporting it this way is a more accurate description of our methods.
} 
Table 5.-SeXual Activity and Contraception Use by Race/Ethnicity

\begin{tabular}{|c|c|c|c|c|c|c|}
\hline & \multicolumn{3}{|c|}{ Ages: $15-19$} & \multicolumn{3}{|c|}{ Ages: $15-44$} \\
\hline & 1988 & 1995 & 2002 & 1988 & 1995 & 2002 \\
\hline \multicolumn{7}{|c|}{ Sexual Activity in Past Three Months } \\
\hline All & 0.43 & 0.40 & 0.36 & 0.78 & 0.77 & 0.72 \\
\hline White NH & 0.43 & 0.40 & 0.38 & 0.79 & 0.79 & 0.74 \\
\hline Black NH & 0.51 & 0.46 & 0.35 & 0.79 & 0.77 & 0.68 \\
\hline Hispanic & 0.31 & 0.45 & 0.31 & 0.72 & 0.73 & 0.70 \\
\hline \multicolumn{7}{|c|}{ No Contraception Use during Last Intercourse in Past Three Months (Conditional on Sexual Activity) } \\
\hline All & 0.23 & 0.32 & 0.17 & 0.22 & 0.25 & 0.24 \\
\hline White NH & 0.20 & 0.30 & 0.11 & 0.20 & 0.23 & 0.21 \\
\hline Black NH & 0.32 & 0.30 & 0.26 & 0.28 & 0.29 & 0.31 \\
\hline Hispanic & 0.31 & 0.47 & 0.37 & 0.28 & 0.32 & 0.31 \\
\hline \multicolumn{7}{|c|}{ Sexually Active in Past Three Months and No Contraception Used at Last Intercourse } \\
\hline All & 0.10 & 0.12 & 0.06 & 0.17 & 0.19 & 0.17 \\
\hline White NH & 0.09 & 0.11 & 0.04 & 0.16 & 0.18 & 0.16 \\
\hline Black NH & 0.16 & 0.14 & 0.09 & 0.22 & 0.22 & 0.21 \\
\hline Hispanic & 0.10 & 0.20 & 0.12 & 0.20 & 0.23 & 0.22 \\
\hline
\end{tabular}

Source: National Survey of Family Growth (NSFG).

assign eligibility to a teen based on recorded household income.

The results of this analysis are reported in columns 3 and 4 of table 4 . Column 3 reports the percentage of women estimated to be eligible for income-based waivers in each population subgroup (other than teens). For all non-teens, income-based waivers increased the reach of Medicaid family planning services to additional $22.5 \%$ of the women. This statistic ranged from $14 \%$ in the state of Washington to $42 \%$ in New Mexico. Younger women, non-white women, and less-educated women were considerably more likely to be eligible for benefits under an income-based waiver. Column 4 reports the ratio of the coefficient estimates in column 1 to the estimated percentage made eligible by an income-based waiver in column 3. This ratio reflects an estimate of the impact of the waiver on the eligible population. We estimate that births fell by almost $9 \%$ among all eligible women and by nearly $15 \%$ for women $20-24$.

\section{Estimating the Impact on Sexual Activity and Contraceptive Use}

\section{A. Data}

We now attempt to corroborate our finding that the expansion of Medicaid family planning services reduced state birth rates by confirming that there was a corresponding behavioral response at the individual level. To do so, we use data from the 1988, 1995, and 2002 cycles of the National Survey of Family Growth (NSFG). These surveys interviewed 8,450,10,847, and 7,643 women between the ages of 14 and 45 in the three survey years, respectively. The samples are nonrepresentative in that they oversample teens and other groups of women, but sampling weights are provided to correct for this. State identifiers are required for this analysis and are not included on public-use NSFG files, but they are available to researchers with permission from the National Center for Health Statistics. ${ }^{9}$

Table 5 reports descriptive statistics regarding sexual activity and contraceptive use for all women and for teens for the years 1988, 1995, and 2002. These statistics update those reported in Levine (2001). In 2002, 36\% of teens and $72 \%$ of women age 15-44 had sexual intercourse in the three months prior to the survey. The large majority of sexually active women practice contraception; $17 \%$ of sexually active teenagers and $24 \%$ of sexually active women failed to use contraception at their last intercourse. Table A1 details the types of contraceptive methods that women in the 2002 NSFG used. Although levels of sexual activity are similar across racial/ethnic groups, there are very significant differences in rates of contraceptive use, particularly for teens.

These data reveal some noteworthy trends in sexual behavior and contraceptive use among teenagers over this time period (there are no obvious trends among women age 15-44). Rates of sexual activity have declined for all teens, particularly for black, non-Hispanic teens. Fewer teens fail to use contraception now than in the past, although Hispanics still have a higher rate of nonuse in 2002 than they did in 1988. With less sexual activity and more contraceptive use, it is not surprising that teen birth rates have been falling. This is further borne out in the statistics in the bottom panel of table 5 showing that fewer teens are both sexually active and not using contraception.

\footnotetext{
${ }^{9}$ All analyses using these state identifiers need to be performed in their Research Data Center in Hyattsville, MD. We thank Christopher Rogers for his assistance in using these data.
} 


\section{B. Econometric Methodology}

To investigate the impact of the expansion of eligibility for Medicaid family planning services on individual behavior, we apply difference-in-difference methods very similar to those we used in our analysis of Vital Statistics birth data. We specify a reduced-form relationship between the implementation of waiver policies and individual-level outcomes. Specifically, we estimate linear probability models of the following form: ${ }^{10}$

$$
\begin{aligned}
Y_{i s t}= & \phi_{o}+\phi_{1}(\text { inc. waiver })_{s t} \\
& +\phi_{2}(\text { dur. waiver })_{s t}+\gamma_{s} \\
& +I(1995)+I(2002)+X_{i s t}+\varepsilon_{i s t} .
\end{aligned}
$$

The dependent variable $Y_{\text {ist }}$ is defined alternately as an indicator for whether an individual engaged in sexual intercourse in the past three months, whether a sexually active individual did not use birth control at last intercourse in the past three months, and whether an individual had unprotected sex in the past three months (the interaction of the other two binary outcome variables). We estimate these linear probability models for all women and for population subgroups. Estimated standard errors are adjusted for clustering at the state level. We weight all regressions by NSFG sampling weights.

The $X$ vector includes indicators for age category, race/ ethnicity, marital status, category of educational attainment, and whether the respondent has children. State-level variables are mainly the same as those described earlier in our analysis using Vital Statistics data. ${ }^{11}$ As before, in regressions run specifically for teenagers, we drop observations from the states of Alabama and New Mexico because the waiver policies in these states explicitly excluded females under the age of 19.

We can also augment this model incorporating a woman's predicted eligibility status for an income-based waiver. ${ }^{12}$ In

\footnotetext{
${ }^{10}$ All results are qualitatively insensitive to the choice of linear probability models rather than probit models. We have also estimated multinomial logit models regarding the impact of waivers on choice of contraceptive method. Unfortunately, the sample size limitations of the NSFG preclude us from drawing statistically meaningful conclusions on this point.

${ }^{11}$ Because we only have three years of data in the NSFG, we do not control for the full set of policies included in the state-level analysis, because there is not enough variation in some of these variables. For example, every state in the data has an SCHIP policy implemented by 2002 and none do in 1988 or 1995 . This policy is thus completely characterized by the indicator variables for survey year.

${ }^{12}$ Conducting a similar exercise for duration-based waivers is complicated by the complexity of predicting eligibility for waivers of this type. To do so, one would need to know Medicaid coverage in the period following each birth (in states with postpartum-based policies) and the woman's income at that time to determine whether she would have had to go off of Medicaid without the waiver. The NSFG does inquire about Medicaid coverage at the time of delivery of each child, but has no retrospective income measure. Using current income as a proxy for income at the time of birth, we were able to identify only fifty women in these data whose deliveries were covered by Medicaid, whose current
}

contrast to the Vital Statistics data described earlier, the NSFG includes information about income that we can use to predict whether a woman was made newly eligible for Medicaid family planning services by the income-based waiver implemented in her state. The waivers extended eligibility to two groups of women: (i) all women whose incomes were between the Medicaid income threshold (which varied widely across states) and the waiver threshold $(133 \%, 185 \%$, and $200 \%$ of the federal poverty line, as described in table 1) and (ii) women whose household income was below the Medicaid threshold but who did not have a qualifying child. To identify these women in the data, we compare an observation's reported household income specified as a proportion of the relevant federal poverty line to the state-specific Medicaid income cutoff in that state and year. We also consider the presence of own children in the household to determine Medicaid categorical eligibility.

We can then interact this "newly eligible" indicator with the income-based waiver indicator variable representing the status of the policy in each woman's state/year of residence and estimate the following regression:

$$
\begin{aligned}
& Y_{i s t}=\phi_{0}+\phi_{1}\left(\text { newelig }_{\text {ist }}\right)+\phi_{2}(\text { inc. waiver })_{s t}
\end{aligned}
$$

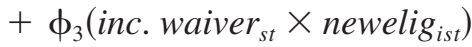

$$
\begin{aligned}
& +\phi_{4}(\text { dur. waiver })_{s t}+\gamma_{s}+I(1995) \\
& +I(2002)+X_{i s t}+\varepsilon_{i s t} \text {. }
\end{aligned}
$$

Note that to control for the "newly eligible" main effect, we need to construct a variable indicating the eligibility status of women in states that did not implement policy waivers. To do this, we consider a hypothetical waiver threshold of $185 \%$ of the federal poverty line, the modal threshold for waivers passed in our set of treatment states. Combining this threshold with information regarding children in the household enables us to predict those women who would become newly eligible for family planning services if implemented in their state. In the formulation of equation (3), the incomebased waiver indicator variable holds constant other broad factors that may be occurring in income-based waiver states following the waiver. The newly eligible indicator holds constant differences that may be occurring between women at income levels needed to qualify for services and other women..$^{13}$ The interaction of these terms highlights whether the behavior of those directly affected by the waivers

income would make her otherwise ineligible for family planning services after the postpartum period expired, and whose most recent birth occurred in a state with a duration-based waiver in place at the time. As a result, we chose not to report an analysis incorporating simulated eligibility for a duration-based waiver.

${ }^{13}$ We have also attempted to separately compare the newly eligible to the two different control groups, the always Medicaid eligible and women with household income above the waiver threshold. In that exercise, the estimated impact of waivers on the eligibles was about the same as it was when we combined control groups, but the sample sizes of these groups, and particularly the "always Medicaid eligible" control groups, were too small to yield statistically significant results. 
Table 6.-Impact of Waivers on Sexual Activity and Contraceptive Use

\begin{tabular}{|c|c|c|c|}
\hline & $\begin{array}{l}\text { Sex in Past } \\
\text { Three Months } \\
\text { (1) }\end{array}$ & $\begin{array}{c}\text { No Birth Control During Last } \\
\text { Intercourse in Past Three Months } \\
\text { (2) }\end{array}$ & $\begin{array}{l}\text { Unprotected Sex in } \\
\text { Past Three Months } \\
\text { (3) }\end{array}$ \\
\hline \multicolumn{4}{|c|}{ Non-Teens $(20-44): N=23,123$} \\
\hline $\begin{array}{l}\text { Income-based waiver } \\
\text { Duration-based waiver }\end{array}$ & $\begin{array}{c}0.045 \\
(0.028) \\
-0.001 \\
(0.029)\end{array}$ & $\begin{array}{c}-0.064 \\
(0.029) \\
0.013 \\
(0.029)\end{array}$ & $\begin{array}{c}-0.043 \\
(0.025) \\
0.009 \\
(0.024)\end{array}$ \\
\hline \multicolumn{4}{|c|}{ Teens (15-19): $N=3,800$} \\
\hline $\begin{array}{l}\text { Income-based waiver } \\
\text { Duration-based waiver }\end{array}$ & $\begin{array}{c}-0.178 \\
(0.053) \\
-0.196 \\
(0.055)\end{array}$ & $\begin{array}{c}0.002 \\
(0.128) \\
0.048 \\
(0.073)\end{array}$ & $\begin{array}{c}-0.022 \\
(0.048) \\
-0.009 \\
(0.031)\end{array}$ \\
\hline \multicolumn{4}{|c|}{ Non-Teens $(20-44): N=23,123$} \\
\hline Income-based waiver & $\begin{array}{c}0.037 \\
(0.028)\end{array}$ & $\begin{array}{r}-0.049 \\
(0.030)\end{array}$ & $\begin{array}{r}-0.033 \\
(0.025)\end{array}$ \\
\hline Income-based waiver $\times$ predicted eligibility & $\begin{array}{c}0.015 \\
(0.024)\end{array}$ & $\begin{array}{r}-0.053 \\
(0.022)\end{array}$ & $\begin{array}{r}-0.033 \\
(0.019)\end{array}$ \\
\hline Predicted eligibility & $\begin{array}{r}-0.007 \\
(.013)\end{array}$ & $\begin{array}{c}-0.011 \\
(0.016)\end{array}$ & $\begin{array}{c}-0.002 \\
(0.014)\end{array}$ \\
\hline Duration-based waiver & $\begin{array}{c}0.007 \\
(0.025)\end{array}$ & $\begin{array}{c}0.011 \\
(0.028)\end{array}$ & $\begin{array}{c}0.008 \\
(0.023)\end{array}$ \\
\hline
\end{tabular}

Notes: The top two panels report the results of estimating equation (2) with indicator variables for a main waiver effect for each type of waiver included in the model. For non-teen women, we additionally estimate a model that interacts an indicator for an income-based waiver with another variable indicating whether the individual is predicted to be covered by the waiver, controlling for predicted eligibility main effect. These regressions are reported in the third panel. Standard errors are adjusted for clustering at the state level and are reported in parentheses. All regressions control for the following individual characteristics: ratio of income to poverty threshold, an indicator for income below $185 \%$ of the poverty line (as a proxy for income eligibility if waiver in effect), age group (where appropriate), race/ethnic group (where appropriate), education group (except for teens), marital status, and whether the respondent has any children living in her household. All regressions also control for the state-year unemployment rate, the maximum welfare benefit for a fact

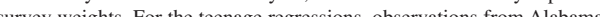
survey weights. For the teenage regressions, observations from Alabama and New Mexico are dropped from the analysis sample because these states implemented income-based waivers that explicitly did not apply
to women under the age of 19 .

changes in response. Because we are concerned about imputing eligibility for teens based on the difficulty of measuring their income, we use this approach for non-teens only.

The reader should note that this is a restricted version of a more general triple-difference estimation strategy, as described in Gruber (1994). The main difference is that our model restricts the coefficients on the state and year fixed effects to be constant across women in different eligibility categories. When we relax this restriction, we find that our data are not sufficiently powerful to separately identify all of the effects without a sizable impact on the standard errors of our variables of interest. With about 23,000 observations over three years and 51 states, combined with an eligibility rate of about $25 \%$, the unrestricted model leaves, on average, about 37 eligible women in each state to identify differences in both the state and year fixed effects and the relevant policy interaction. There is not enough statistical power for this to be a useful analysis. Despite this limitation, we believe that our results in this section provide sufficient supporting evidence of our other findings.

\section{Results: Sexual Activity and Contraceptive Use}

Table 6 reports the estimated coefficients of interest from equation (2) for teens and non-teens and equation (3) for non-teens only for the three dependent variables-sex in past three months, no birth control during last intercourse in the past three months, and unprotected sex in the past three months. The results in the top panel (from equation [2]) for non-teens indicates that there was no statistically significant impact of the waivers on the likelihood of sex in the past three months, but that income-based waivers increased the likelihood of contraceptive use among sexually active women. For teens, large standard errors make it difficult to conclude much. We do find a negative and statistically significant impact of income-based waivers on teen sexual activity, but we are skeptical of this finding for two reasons. First, we believe it is counterintuitive; it is hard to imagine how the introduction of family planning services and the distribution of contraception would lead to more abstinence. Second, these estimates are obtained from models that include no within-state control group. Given the rather significant downward trend in teen birth rates over this period, our inability to control for differential trends across states that may be related to the decline in teen births is an important limitation of this analysis.

The bottom panel of the table switches to a tripledifference identification strategy that incorporates predicted eligibility for income-based waivers, as in equation (3). For all non-teens, we see that there is little evidence suggesting that sexual activity is affected, but we continue to find evidence of increased use of contraception. Over $5 \%$ fewer sexually active women failed to use contraception at their last intercourse and $3.3 \%$ fewer women could be identified as having unprotected sex in the past three months. Both estimates are significant at the 5\% level. These results 
suggest that the reason that birth rates fell in response to income-based family planning waivers is because they increase the use of contraception.

We also attempted to reconcile the estimated impact on sexual activity and contraceptive use with the estimated reduction in births obtained from Vital Statistics. We ultimately concluded that such a comparison required too many unverifiable assumptions and the results of this exercise were sensitive to the parameter values we chose. In theory, if we had complete data on the likelihood of becoming pregnant in a given month in the absence of contraception (incorporating both biological capacity and frequency of sexual activity) and the intensity of contraceptive use along with its failure rate, we could simulate how an increase in the likelihood of using contraception would alter birth rates. Unfortunately, our measure of contraceptive use-contraception at last intercourse in the past three months-is insufficient for that purpose.

\section{Discussion}

\section{A. Estimate of Cost per Birth Avoided}

Since waiver programs require federal expenditures to cover the cost of the family planning services provided, a reasonable question is how much these services cost per birth avoided. We can integrate our estimates along with outside information regarding the estimated cost per program participant to arrive at this figure. According to the Guttmacher Institute (2007b), public spending on family planning services totaled $\$ 1.26$ billion in FY 2001. According to Frost, Frohwirth, and Purcell (2004), 6.7 million women received services at publicly provided family planning clinics in 2001. This means that the average cost per woman served is $\$ 188$. Of course, the cost estimate that we really need is the marginal cost of providing additional services to women brought into the program in the presence of waivers, but no such evidence exists. Instead, we will assume that there is a constant marginal cost and continue to use this $\$ 188$ figure.

We can combine this figure with the results provided in this paper to provide a ballpark estimate of the cost of these services per birth avoided. Our analysis of MSIS data on Medicaid family planning receipt showed that incomebased waivers increased the percentage of women receiving services by 5.3 percentage points (table 2 -model with quadratic trends). This means that for every 1,000 women of childbearing age, 54 more obtained family planning through Medicaid after the waiver than before. The birth rate in those states in 1992, before the waivers, stood at a level of about 74 births per 1,000 women. Our estimates in table 3 suggest that income-based waivers reduced births by $2 \%$, or about 1.5 births per year per 1,000 women. Combining these two estimates, we conclude that one birth was avoided for every 36 additional Medicaid family planning recipients. At $\$ 188$ per recipient, this means that the cost of avoiding one additional birth through an income-based waiver is roughly $\$ 6,800$. Earlier in the paper, we estimated that income-based family planning waivers had a $22 \%$ to $44 \%$ take-up rate. This means that one birth was avoided for every 82 to 164 women made eligible.

\section{B. Impact of Waivers Compared with Other Interventions}

An alternative framework for thinking about the impact of these waivers is to compare the reduction in fertility associated with them to that associated with other policy changes that could accomplish this goal. First, it is important to recognize that past attempts to increase contraceptive use generally have not been successful in reducing teen fertility, as described earlier. Second, the most recent policy measure aimed at reducing nonmarital and/or teen fertility is welfare reform. In previous work we have found that family cap policies implemented as part of welfare reform in the early and mid-1990s were not effective at reducing birth rates among targeted women (Kearney, 2004; Levine, 2002). In their extensive review of studies examining the impacts of welfare reform policies more generally, Grogger and Karoly (2005) conclude that "there is little evidence that welfare reform as a whole lowers childbearing" (p. 196).

More broadly, researchers have examined the incentive role of the welfare system on teen and nonmarital childbearing. Moffitt (1998) reviews this literature and reports that while no consensus exists on the magnitude of the impact, the wide range of point estimates across studies does suggest that there is some positive causal relationship between welfare benefits and the likelihood of female headship. This suggests some role, potentially quite modest, for lowering rates of fertility through a reduction in benefits. Third, from a more historical perspective, abortion legalization in the early 1970s was one policy change that led to a significant reduction in (presumably unwanted) fertility, particularly among teens. Levine et al. (1999) find that abortion legalization reduced overall fertility by $4 \%$ and teen fertility by $12 \% .{ }^{14}$ With the exception of the greater impact associated with a radical policy change like abortion legalization, our estimates indicate that family planning waivers represent a relatively successful attempt at reducing rates of (presumably unwanted) births.

\section{Contribution to Decline in Teen Fertility Rate}

Earlier, we discussed the fact that teen fertility rates declined dramatically since the early 1990s, falling from a rate of 60.3 births per 1,000 women aged 15-19 in 1990 to a rate of 43.0 in 2002 (Guttmacher Institute, 2006). We also

\footnotetext{
14 These estimates are probably somewhat misleading because they incorporate travel between states that occurred during the period in which abortion was legal in some states, but not others. Levine et al. estimate that if there were no travel between states (that is, moving from a total ban on abortion to legal abortion), the overall birth rate would have fallen by over $10 \%$. Presumably, taking travel into account in estimating the teen fertility effect would also lead to a substantially higher estimate.
} 
know that the introduction of an income-based family planning waiver is estimated to reduce the teen birth rate by $4.2 \%$ (in a model with quadratic state trends). Although the impact of the waivers was substantial, they clearly can explain very little of the downward trend in teen fertility. Over our sample period, only $22 \%$ of teens live in the seven states instituting income-based waivers by 2002 . This means that the national teen birth rate would be predicted to decline by $0.22 \times 0.042 \times 60.3=0.56$, or $3 \%$ of the overall decline.

\section{Conclusion}

This study took advantage of the nature of the waiver implementation process that led some states to expand access to contraception for some women. We began by presenting evidence that these income-based waivers did indeed increase the number of women receiving family planning services through Medicaid by two to three times. We then reported the results of models for teens and nonteens, which showed that births fell as a result. Incomebased waivers were found to reduce births by $1.7 \%$ to $2 \%$ for non-teens and $4.2 \%$ to $4.7 \%$ for teens. Incorporating information on predicted increases in eligibility brought about by state income-based waiver policies, we estimate that births fell by $8.9 \%$ among newly eligible women age 20-44. We further document that this impact can be attributed to increased contraceptive use among sexually active women.

We used the results of our analysis to show that incomebased family planning waivers reduced one birth for every 36 additional Medicaid family planning recipients. Combining this with external information regarding the cost of family planning provision, we estimate the cost of preventing an unwanted birth to be around $\$ 6,800$. Based on our review of other interventions designed to reduce unwanted births, this seems like a relatively effective policy intervention.

Beyond the cost-effectiveness of this policy, our results also raise the possibility that family planning waivers may have improved women's outcomes more broadly. If women are better able to control their fertility, then this may relax a constraint that has restricted their options in other aspects of their lives. For instance, one might expect educational attainment and/or labor market outcomes to improve for women. This is an important avenue for future research to explore.

\section{REFERENCES}

Averett, Susan L., Daniel I. Rees, and Laura Argys, "The Impact of Government Policies and Neighborhood Characteristics on Teenage Sexual Activity and Contraceptive Use," American Journal of Public Health 92:11 (2002), 1773-1778.

Bailey, Martha J., "More Power to the Pill: The Impact of Contraceptive Freedom on Women's Life Cycle Labor Supply," Quarterly Journal of Economics 121:1 (2006), 289-320.
Besley, Timothy, and Anne Case, "Unnatural Experiments? Estimating the Incidence of Endogenous Policies," Economic Journal 110:467 (2000), F672-F694.

Broaddus, Matthew, Shannon Blaney, Annie Dude, Jocelyn Guyer, Leighton $\mathrm{Ku}$, and Jaia Peterson, Expanding Family Coverage: States' Medicaid Eligibility Policies for Working Families in the Year 2000 (Washington, DC: Center on Budget and Policy Priorities, 2002).

Council of Economic Advisers, Technical Report: Explaining the Decline in Welfare Receipt, 1993-1996 (Washington, DC: Executive Office of the President of the United States, 1997).

Technical Report: Economic Expansion, Welfare Reform, and the Decline in Welfare Caseloads: An Update. (Washington, DC: Executive Office of the President of the United States, 1999).

Crouse, Gil, State Implementation of Major Changes to Welfare Policies. 1992-1998 (Washington, DC: Office of Human Services Policy, Assistant Secretary for Planning and Evaluation, U.S. Department of Health and Human Services, 1999).

DiCenso, Alba, Gordon Guyatt, A. Willan, and L. Griffith, "Interventions to Reduce Unintended Pregnancies among Adolescents: Systematic Review of Randomized Controlled Trials," British Medical Journal 324:7351 (2002), 1426-1434.

Edwards, Joanna, Janet Bronstein, and Kathleen Adams, Evaluation of Medicaid Family Planning Demonstrations (Alexandria, VA: CNA Corporation, 2003).

Finer, Lawrence B., and Stanley K. Henshaw, "Abortion Incidence in the U.S. in 2000," Perspectives on Sexual and Reproductive Health 35:1 (2003), 6-15.

Frost, Jennifer J., Lori Frohwirth, and Alison Purcell, "The Availability and Use of Publicly Funded Family Planning Clinics: U.S. Trends, 1994-2001," Perspectives on Sexual and Reproductive Health 36:5 (2004), 206-215.

Frost, Jennifer J., Adam Sonfield, and Rebecca Benson Gold, "Estimating the Impact of Expanding Medicaid Eligibility for Family Planning Services," Guttmacher Institute occasional report 28 (2006).

Gallagher, L. Jerome, Megan Gallagher, Kevin Perese, Susan Schreiber, and Keith Watson, "One Year after Federal Welfare Reform: A Description of State Temporary Assistance for Needy Families (TANF) Decisions as of October 1997," Urban Institute occasional paper no. 6 (1998).

Gold, Rachel Benson, "Doing More for Less: Study Says State Medicaid Family Planning Expansions Are Cost-Effective," The Guttmacher Report on Public Policy 7:1 (2004), 1-2.

Gold, Rachel Benson, and Adam Sonfield, "Reproductive Health Services for Adolescents under the State Children's Health Insurance Program," Family Planning Perspectives 33:2 (2001), 81-87.

Grogger, Jeffrey, and Lynn A. Karoly, Welfare Reform: Effects of a Decade of Change (Cambridge, MA: Harvard University Press, 2005).

Gruber, Jonathan, "The Incidence of Mandated Maternity Benefits," The American Economic Review 84:3 (1994), 622-641.

Guttmacher Institute, Issues in Brief: The Limitations of U.S. Statistics on Abortion (New York: Alan Guttmacher Institute, 1997).

U.S. Teenage Pregnancy Statistics: National and State Trends and Trends by Race and Ethnicity (New York: Alan Guttmacher Institute, 2006).

State Policies in Brief as of June 2006: State Medicaid Family Planning Eligibility Expansions, http://www.guttmacher.org/ statecenter/spibs/spib_SMFPE.pdf (2007a). Accessed March 28, 2007.

Public Funding for Contraceptive, Sterilization and Abortion Services. FY 1980-2001. http://www.guttmacher.org/pubs/ fpfunding/index.html (2007b). Accessed March 28, 2007.

Henshaw, Stanley K., "Teenage Abortion and Pregnancy Statistics by State, 1992," Family Planning Perspectives 29:3 (1997), 115-122.

Henshaw, Stanley K., and Dina J. Feivelson, "Teenage Abortion and Pregnancy Statistics by State, 1996," Family Planning Perspectives 32:6 (2000), 272-280.

Kearney, Melissa S., "Is There an Effect of Incremental Welfare Benefits on Fertility Behavior? A Look at the Family Cap," Journal of Human Resources 39:2 (2004), 295-325.

Kirby, Douglas, No Easy Answers: New Research Findings on Programs to Reduce Teen Pregnancy (Washington, DC: National Campaign to Prevent Teen Pregnancy, 1997). 
Emerging Answers: New Research Findings on Programs to Reduce Teen Pregnancy (Washington, DC: National Campaign to Prevent Teen Pregnancy, 2001).

Levine, Phillip B., "The "Sexual Activity and Birth Control Use of American Teenagers" (pp. 167-218) in Jonathan Gruber (Ed.), An Economic Analysis of Risky Behavior among Youths (Chicago: University of Chicago Press, 2001).

"The Impact of Social Policy and Economic Activity Throughout the Fertility Decision Tree," National Bureau of Economic Research working paper no. 9021 (2002).

Sex and Consequences: Abortion, Public Policy, and the Economics of Fertility (Princeton, NJ: Princeton University Press, 2004).

Levine, Phillip B., Douglas Staiger, Thomas J. Kane, and David J. Zimmerman, "Roe v. Wade and American Fertility," American Journal of Public Health 89:2 (1999), 199-203.

Lindrooth, Richard C., and Jeffrey S. McCollough, "The Effect of Medicaid Family Planning Expansions on Unplanned Births," Women's Health Issues 17:2 (2007) 66-74.

Lundberg, Shelly, and Robert D. Plotnick, "Effects of State Welfare, Abortion and Family Planning Policies on Premarital Childbearing Among White Adolescents," Family Planning Perspectives 22:6 (1990), 246-251, 275.

Martin, Joyce A., Brady E. Hamilton, Paul D. Sutton, Stephanie J. Ventura, Fay Menacker, and Martha L. Munson, "Births: Final Data for 2003," National Vital Statistics Reports 54:2 (2005).

Mellor, Jennifer M., "The Effect of Family Planning Programs on the Fertility of Welfare Recipients: Evidence from Medicaid Claims," Journal of Human Resources 33:4 (1998), 866-895.
Moffitt, Robert, "The Effect of Welfare on Marriage and Fertility" (pp. 50-97), in Robert Moffitt (Ed.), Welfare, the Family, and Reproductive Behavior (Washington, DC: National Academy Press, 1998).

National Center for Health Statistics, "Fertility, Family Planning, and Reproductive Health of U.S. Women: Data from the 2002 National Survey of Family Growth," Vital and Health Statistics series 23, no. 5 (Hyattsville, MD: National Center for Health Statistics, 2005).

Paton, David, "The Economics of Family Planning and Underage Conceptions," Journal of Health Economics 21:2 (2002), 207-225.

Rowe, Gretchen, Kevin McManus, and Tracy Roberts, The Welfare Rules Databook: State Policy as of July 2001 (Washington, DC: Urban Institute, 2004)

Rowe, Gretchen, with Victoria Russell, The Welfare Rules Databook: State Policy as of July 2002 (Washington, DC: Urban Institute, 2004).

Rowe, Gretchen, with Jeffrey Versteeg, The Welfare Rules Databook: State Policy as of July 2003 (Washington, DC: Urban Institute, 2005).

U.S. Department of Health and Human Services, Setting the Baseline: A Report on State Welfare Waivers (Washington, DC: Office of Human Services Policy, Assistant Secretary for Planning and Evaluation, U.S. Department of Health and Human Services, 1997).

Wall Street Journal Online, "Large Majorities Support More Access to Birth Control Information, and Agree that It Is a Good Way to Prevent Abortions," Wall Street Journal Online: Health Care Poll 5:10 (June 22, 2006).

\section{APPENDIX}

Table A1.-Form of Last Birth Control among Sexually Active Women

\begin{tabular}{|c|c|c|c|c|c|c|c|}
\hline & \multirow[b]{2}{*}{$\begin{array}{l}\text { Percentage Using Any } \\
\text { Method at Last } \\
\text { Intercourse }\end{array}$} & \multicolumn{6}{|c|}{ Percentage of Women Using Method, Conditional on Contraceptive Use } \\
\hline & & $\begin{array}{l}\text { Natural } \\
\text { Methods } \\
\text { (1) }\end{array}$ & $\begin{array}{c}\text { Condom } \\
\text { (2) }\end{array}$ & $\begin{array}{l}\text { Pill } \\
(3)\end{array}$ & $\begin{array}{l}\text { Female } \\
\text { Insert } \\
\text { (4) }\end{array}$ & $\begin{array}{l}\text { DepoProvera/ } \\
\text { Norplant } \\
\text { (5) }\end{array}$ & $\begin{array}{c}\text { Sterile } \\
\text { (Either Partner) } \\
\text { (6) }\end{array}$ \\
\hline All women $(N=18,602)$ & 74.3 & 6.1 & 19.6 & 28.4 & 5.4 & 2.9 & 37.6 \\
\hline Teens $(N=1,410)$ & 74.2 & 6.2 & 40.9 & 44.6 & 1.6 & 6.2 & 0.5 \\
\hline Non-teens $(N=17,192)$ & 74.3 & 6.1 & 17.7 & 26.9 & 5.7 & 2.6 & 40.9 \\
\hline Unmarried $(N=7,816)$ & 77.4 & 5.8 & 25.4 & 38.9 & 4.4 & 4.4 & 21.1 \\
\hline Less than HS $(N=3,221)$ & 68.3 & 4.4 & 13.8 & 17.2 & 4.9 & 4.3 & 55.3 \\
\hline White non-Hispanic $(N=11,017)$ & 76.8 & 6.1 & 18.5 & 29.2 & 5.4 & 2.2 & 38.6 \\
\hline Black non-Hispanic $(N=4,503)$ & 69.7 & 3.8 & 20.5 & 27.6 & 4.6 & 5.3 & 38.3 \\
\hline Hispanics $(N=2,502)$ & 65.1 & 7.3 & 22.0 & 25.9 & 5.6 & 5.8 & 33.3 \\
\hline No children in household $(N=6,530)$ & 72.7 & 6.2 & 25.6 & 44.0 & 4.7 & 2.2 & 17.3 \\
\hline Children in household $(N=12,072)$ & 75.2 & 6.1 & 16.0 & 19.0 & 5.8 & 3.4 & 49.8 \\
\hline
\end{tabular}

